\title{
Pemanfaatan Saluran Irigasi untuk pembangkit Piko Hidro di Dusun Pagi Penebel Tabanan
}

\author{
I Putu Ardana ${ }^{1}$, Lie Jasa ${ }^{2}$,
}

\begin{abstract}
A pico hydro turbines will be able to spin at a certain speed, the rotation of turbine depends on the magnitude of driving force of water that falls on the blades. Continuity the flow of water striking the turbine blades will determine the electrical energy generated successfully. Limited water supply throughout the year during the dry season, due to the encroachment unmonitored and cause flooding during the rainy season. In this paper the authors propose how to make a prototype pico hydro turbines, which can uses of the water irrigation channels efficiently, especially in the dry season. By designing the amount of the angle of attack of the blades turbines will be capable to producing a maximum rpm. In this research by using a turbine diameter of $40 \mathrm{~cm}$, width $30 \mathrm{~cm}$, blade number 16, a height of 7 meters with the curvature of the blade angle $\beta$ of 150, capable of producing the turbine shaft rpm of 130 ..
\end{abstract}

Intisari- Sebuah turbin piko hidro akan mampu berputar dengan kecepatan tertentu, putaran tersebut sangat tergantung pada besarnya daya dorong air yang jatuh pada sudu turbin. Kontinyuitas dari aliran air yang menumbuk sudu turbin akan menentukan energi listrik yang berhasil dihasilkan. Keterbatasan sumber air sepanjang tahun pada saat musim kemarau, akibat adanya perambahan hutan yang tidak terpantau dan mengakibatkan terjadinya banjir saat musim penghujan. Dalam paper ini penulis mengajukan bagaimana membuat prototipe turbin piko hidro, yang dapat manfaatkan air saluran irigasi secara efisien terutama di musim kemarau. Dengan mengatur besarnya sudut serang dari sudu-sudu turbin akan mampu menghasilkan rpm yang maksimal. Dalam penelitian ini dengan menggunakan diameter turbin sebesar 40 $\mathrm{Cm}$, lebar $30 \mathrm{Cm}$, jumlah sudu 16, ketinggian 7 meter dengan sudut kelengkungan sudu $\beta$ sebesar 150, mampu menghasilkan rpm pada poros turbin sebesar 130 .

Kata Kunci- Turbin, piko hidro, generator, sudu.

\section{PENDAHULUAN}

Tabanan terkenal sejak dahulu sebagai lumbung berasnya pulau Dewata Bali. Potensi alam yang ada memungkinkan dimanfaatkan sebagai salah satu usaha untuk mengatasi masalah kemiskinan[1]. Lapangan kerja yang terbatas, aktivitas masyarakat pedesaan yang belum mendapat sentuhan teknologi. Dengan memanfaatkan energi terbarukan sebagai upaya untuk mengurangi ketergantungan pada energi fosil. Piko hidro bisa disandingkan dengan peternakan ikan pada saluran irigasi yang airnya digunakan secara bersama sama. Masyarakat pedesaan selama ini memang masih menjadikan usaha peternakan ikan sebagai usaha sampingan. Menjadikan dalam hal pemanfaatan energi listrik untuk membantu usaha

${ }^{1}$ Dosen Jurusan Teknik Elektro dan Komputer Fakultas Teknik Universitas Udayana, Jln. Jalan Kampus Bukit Jimbaran 80361 INDONESIA (telp: 0361-703315; fax: 0361-703315; e-mail antennakabeh@gmail.com).

${ }^{2}$ Dosen Jurusan Teknik Elektro dan Komputer Fakultas Teknik Universitas Udayana, Jln. Jalan Kampus Bukit Jimbaran 80361 INDONESIA (telp: 0361-703315; fax: 0361-703315; e-mail: liejasa@unud.ac.id) budidaya peternakan ikan air deras merupakan sesuatu yang baru.

Sumber daya alam yang tersedia memang belum dimanfaatkan secara maksimal, akibat keterbatasan pengetahuan, sentuhan teknologi. Dusun Pagi, Desa Senganan, Kecamatan Penebel, Kabupaten Tabanan Bali. Selama ini masyarakatnya adalah petani sawah, sedangkan budidaya ikan air deras hanya bersifat sambilan. Menggabungkan sentuhan teknologi dan kehidupan sehari-hari masyarakat perlu dilakukan penelitian berkatian dengan pemanfaatan piko hidro[2] yang mampu menghasilkan energi listrik dalam sekala kecil sesuai dengan potensi yang ada.

Menurut penelitian yang dilakukan oleh Maher[3], sebuah piko hidro akan mengalami rugi-rugi pada penstock sebesar $30 \%$, pada turbin sekitar $30 \%$ dan pada generator sampai dengan 20\%. Data ini menunjukkan bahwa, bila rugi-rugi pada penstock dan turbin dapat dikurangi, maka energi yang dihasilkan oleh piko hidro akan meningkat.

Penelitian mengenai mikro hidro di dusun Gambuk, Pupuan Tabanan Bali[4],[1],[5] terbukti mampu menghasilkan energi listrik dalam sekala kecil dan murah. Namun karena sumber air yang terbatas, mikro hidro tersebut tidak bisa beroperasi sepanjang tahun. Berbeda dengan potensi sumber air yang ada didusun Pagi Desa Penebel Tabanan, air mengalir sepanjang tahun karena merupakan saluran irigasi teknis.

Penelitian ini adalah merancang sebuah prototype turbin piko hidro yang mampu menghasilkan energi listrik dalam sekala kecil[6] yang nantinya diintegrasikan dengan perikanan air deras masyarakat dusun Pagi. Model turbin yang dirancang berbentuk cross flow dengan ketinggian (head) mencapai 7 meter dengan debit air kurang lebih 40 liter perdetik, dan debit air relative tetap sepanjang tahun.

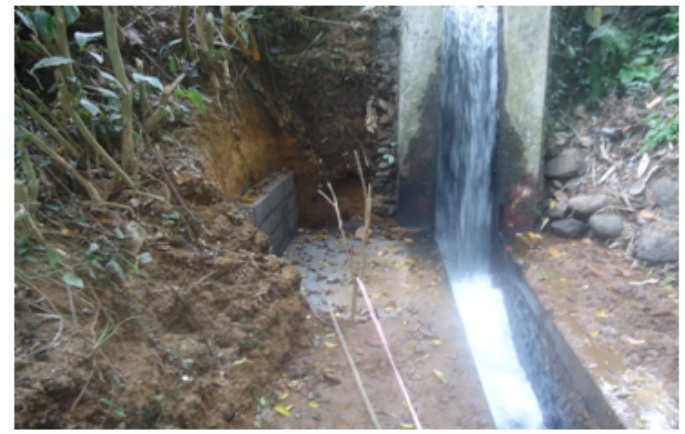

Gambar 1: Saluran Irigasi Di Dusun Pagi yang dimanfaatkan sebagai pembangkit Piko Hidro.

Penelitian ini menggunakan prinsip aliran berlanjut. Artinya air akan mengalir tidak dilakukan proses bendung. Konsep ini dikenal dengan tipe run-of-river. Pembangkit piko hidro tipe run-of-river lebih menguntungkan dibandingkan dengan pembangit lainnya[3]. Pada penelitian ini rancangan turbin dibuat kecil dan ditekankan untuk piko hidro yang

$$
\text { p-ISSN:1693 - 2951; e-ISSN: 2503-2372 }
$$


beroperasi di saluran irigasi. Artinya piko hidro nantinya dapat dioperasikan tidak memerlukan bendungan untuk menampung air. Namun yang menjadi pembeda dari penelitian ini adalah konsep run-of-river untuk piko hidro[7],[8],[9], dimana desain turbin tetap memperhatikan parameter input ketinggian $(\mathrm{H})$, debit air (Q) dan kecepatan aliran (v).

\section{Turbin CROSS Flow}

Turbin Cross flow atau sering dikenal dengan turbin Banki terdiri dari dua bagian utama turbin yaitu nozzle dan runner. Nozzle merupakan bagian yang diam sedangkan runner merupakan bagian yang bergerak. Runner dibuat dari dua buah piringan sejajar yang digabungkan oleh sederetan sudu melengkung di bagian tepi. Teori tentang turbin Banki[10] ditulis pada bulletin series no.25 Engineering Experiment station Oregon state system of higher Education Februari 1949. Pada penelitian dilakukan analisis matematika dan model eksperimen dilokasi. Pembuatan model ini didasarkan pada data seperti; diameter turbin $\left(\mathrm{D}_{1}\right)$, lebar turbin $(\mathrm{W})$, jumlah sudu (N), debit air (Q) dan beban generator, sudut kelengkungan sudu.

Alur jet yang melalui turbin dengan asumsi bahwa titik pusatnya di titik A pada Gambar 2 [10]. $\mathrm{V}_{1}$ adalah kecepatan absolut air yang membentuk sudut $\alpha_{1}$ dengan garis singgung pinggiran roda. Kecepatan aliran air sebelum masuk adalah :

$$
V_{1}=C \sqrt{2 g h}
$$

Dimana $\mathrm{V}_{1}=$ kecepatan absolut air $(\mathrm{m} / \mathrm{s}), \quad \mathrm{C}=$ koefisien nozzle, $\mathrm{g}=$ gravitasi $\left(\mathrm{m} / \mathrm{s}^{2}\right), \mathrm{h}=$ ketinggian $(\mathrm{m})$

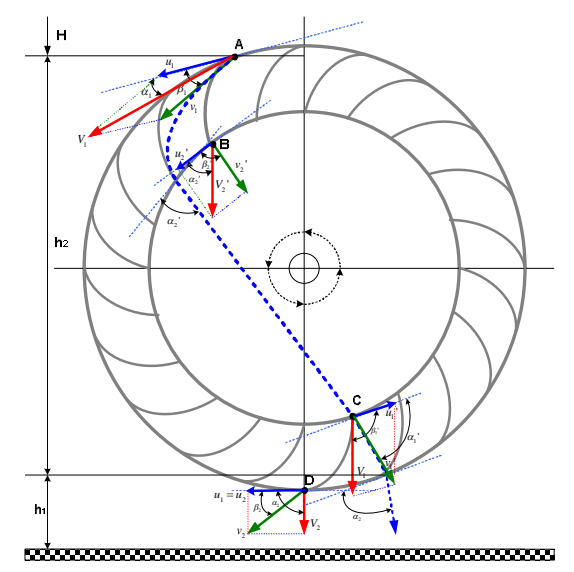

Gambar 2. Jalur air melewati turbin[10]

Kecepatan relatif air masuk $\mathrm{v}_{1}$ dapat ditemukan, bila kecepatan keliling $\mathrm{u}_{1}$ roda pada titik tersebut diketahui. $\beta_{1}$ adalah sudut arah maju dari dua kecepatan $\mathrm{v}_{1}$ dan $\mathrm{u}_{1}$. Untuk membuat efisiensi menjadi maksimum, sudut sudu harus sama dengan nilai $\beta_{1}$. Jika garis lengkung $A B$ menggambarkan sudu pada Gambar 3, maka pada titik $\mathrm{B}_{2}$ ' adalah kecepatan relatif saat air keluar dari sudu bagian dalam. Sudut $\beta_{2}$ ' adalah sudut yang terbentuk antara kecepatan relatif keluar sudu $v_{2}$ ' dengan kecepatan keliling roda $\mathrm{u}_{2}$ 'pada titik B. Kecepatan absolut air saat keluar sudu, $\mathrm{V}_{2}$ ' dapat dihitung dari nilai $\mathrm{v}_{2}$, , sudut $\beta_{2}{ }^{\text {' }}$ dan kecepatan $\mathrm{u}_{2}$ '. Sudut antara kecepatan absolut air $\left(\mathrm{V}_{2}{ }^{\prime}\right)$ dan kecepatan roda $\left(\mathrm{u}_{2}{ }^{\prime}\right)$ pada titik $\mathrm{B}$ adalah $\alpha 2$ '. Jalur absolut air mengalir diatas sudu AB dapat dihitung, pada titik aktual saat air meninggalkan sudu. Dengan asumsi kecepatan absolut air tidak berubah $\mathrm{V}_{2}$, , pada titik $\mathrm{C}$, dimana air masuk kembali ke roda, dapat ditemukan. $\mathrm{V}_{2}$ ' pada titik ini akan menjadi $\mathrm{V}_{1}$, dan jalur air tetap diatas sudu CD dari mengalir dari titik $\mathrm{C}$ ke D [10] dapat dipastikan. Dengan demikian maka

$$
\alpha_{1}{ }^{\prime}=\alpha_{2}{ }^{\prime}, \beta_{1}{ }^{\prime}=\beta_{2}{ }^{\prime}, \beta_{1}=\beta_{2}
$$

hubungannya saat sudut dari sudu yang sama.
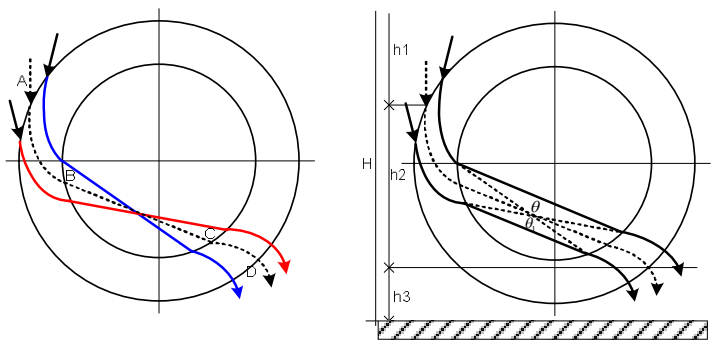

Gambar 3 Interferensi aliran air melalui roda[10]

Daya sebuah turbin Banki dapat dihitung berdasarkan persamaan daya keluaran. Berikut adalah persamaan daya untuk turbin adalah :

$$
P=\left(\frac{\gamma Q}{g}\right)\left(V_{1} \cos \alpha_{1}+V_{2} \cos \alpha_{2}\right) u_{1}
$$

persamaan (2) dapat diturunkan dari gambar segitiga kecepatan yang ditunjukkan Gambar 2. Pergerakan air turbin dari titik A selanjutnya melalui titik B dan mendorong kembali pada titik C dan keluar melalui titik D[11]. Ilustrasi pergerakan air ditunjukkan pada gambar 3,

\section{DESAIN PIKO HIDRO}

Piko hidro ini dirancang dengan menggunakan turbin cross flow dengan diameter sebesar $40 \mathrm{Cm}$, tebal $30 \mathrm{Cm}$, jumlah sudu sebanyak 16 buah dan dengan sudut kelengkungan $\beta$ sebesar $15^{\circ}$. Model rancangan turbin cross flow seperti terlihat pada Gambar 4. Bahan yang digunakan adalah terbuat dari bahan besi plat dengan ketebalan $5 \mathrm{~mm}$. Tujuan menggunakan bahan ini adalah supaya runner mampu menahan dorongan jatuhnya air dari atas secara vertikal dengan kekuatan tertentu. Air yang masuk kedalam runner dengan tekanan yang tinggi akibat pengaruh gaya gravitasi sebesar $9,8 \mathrm{~m} / \mathrm{d}^{2}$. Putaran runner dirancang searah dengan jarum jam, sehingga generator pun dibuat berputar searah jarum jam. Generator yang terpasang adalah dengan kapasitas 3 KVA, karena dipasaran tidak tersedia dalam kapasitas yang lebih kecil. Tali kipas A2 dipasang dari turbin menuju generator. 


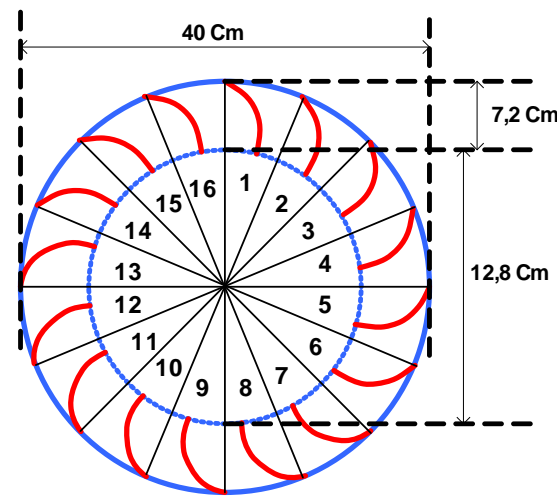

Gambar 4. Desain runner turbin Banki

Selanjutnya runner dipasangkan dengan poros yang terbuat dari besi dengan diameter 2,5 inch. Ditopang dengan fillow yang terletak pada sampirng kiri dan kanan dari runner. Pada ujung sisi sebelah kanan dari runner, poros dibuat lebih panjang dan dipasangkan fulley dengan diameter $60 \mathrm{~cm}$. Tipe pulley yang digunakan adalan tipe A-2, artinya talikipas model A dan berjumlah sebanyak 2 buah. Seperti terlihat pada Gambar 6.

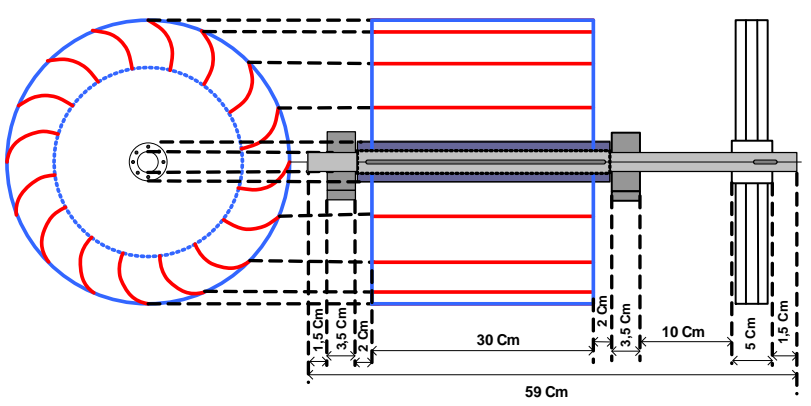

Gambar 5. Disain poros dari runner dan fulley.

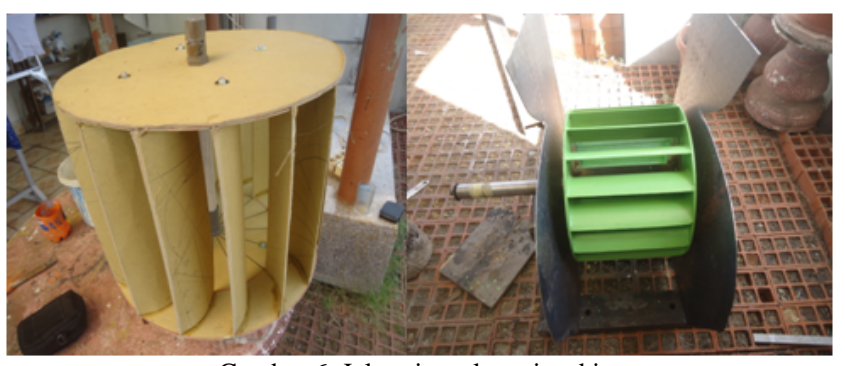

Gambar 6. Jalur air melewati turbin

Pada gambar 6 terlihat model disain dari turbin cross flow yang dibuat, pertama dibuat maket dengan bahan kertas karton. Selanjutnya model tersebut dibawa ke tukang bubut untuk dibuatkan dari bahan besi dengan ukuran yang sama. Pembuatan model dari bahan kertas karton, dibuat dengan dimensi yang sama, tujuannya adalah untuk memudakan proses pembuatan dibengkel berdasarkan ukuran yang sama dengan ukuran yang akan dibuat.

Putu Ardana: Pemanfaatan Saluran Irigasi untuk ...
Runner dan poros yang sudah dipasang menjadi satu, ditopang dengan fillow ditempatkan pada rumah runner dengan komposisi yang tepat, agar tidak terjadi gesekan antara runner dengan tempatnya, sekaligus mengurangi celah yang terjadi. maka perlu dilakukan penelitian yang seksama untuk mendapatkan hasil yang paling mendekati sempurna. Karena model ini yang menentukan besarnya energi air yang berubah menjadi energi putran.

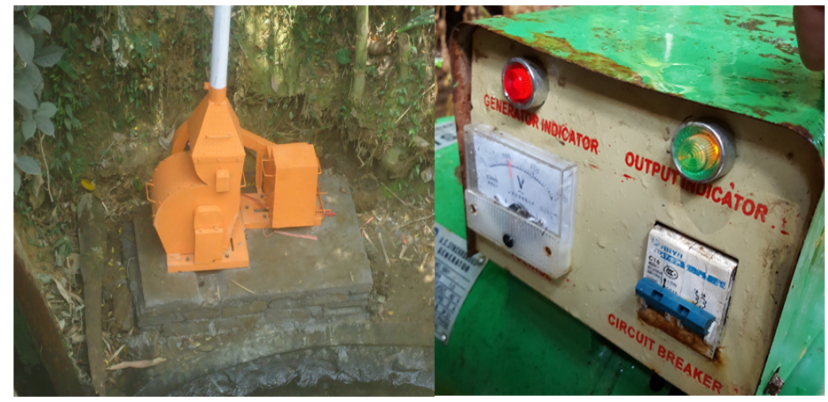

Gambar 7. Desain runner turbin Banki

Rumah dari runner dipasang pada tempat yang sudah ditentukan dengan posisi pipa jatuh dengan arah tegak lurus. Tujuannya adalah untuk mendapatkan percepatan gravitasi yang maksimal. Generator dipasang disebelah kanan dari fulley turbin, namun dalam penelitian ini, tidak mampu menghasilkan putaran yang maksimal karena talikipas basah akibat percikan air yang jatuh dari turbin. Mesti tidak bahkan penutup talikipas yang menahan air tidak mengenai talikipas saat berputar.

Pengukurang putaran dilakukan dengan tachometer yang ditempelkan pada poros runner. Hasil pengukuran putaran (rpm) pada poros turbin dilakukan dalam dua kondisi. Pada kondisi pertama dimana tower air, yang merupakan input dari pipa penstock pada posisi tidak terisi penuh air. Dalam artian air yang masuk kedalam tower tidak sampai tumpah. Kondisi ini menandakan air yang masuk seimbang jumlahnya dengan air yang keluar dari pipi penstock. Hasil pengukuran rpm dilakukan dalam 13 kali pengambilan data dengan menggunakan tacho meter didapatkan nilai rata - rata sebesar 122,68 ntuk data ke-1, dan sbesar 124,05 untuk data yang ke-2. Seperti ditunjukkan pada Gambar 8.

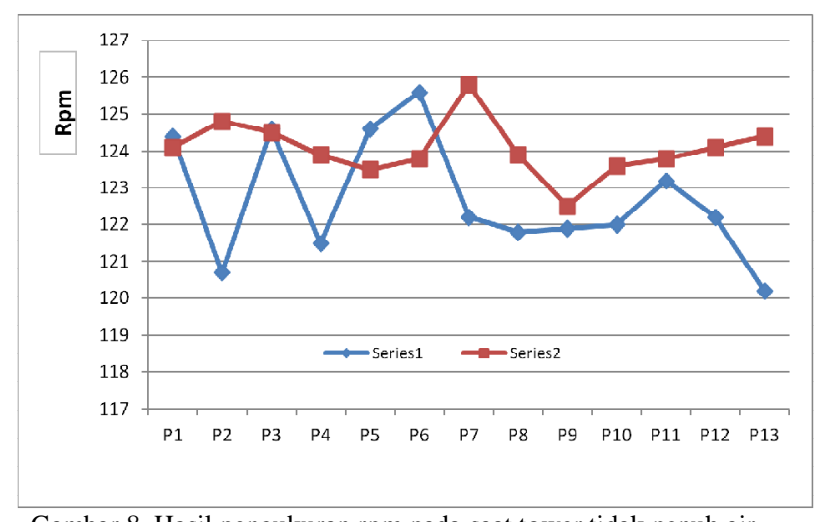

p-ISSN:1693 - 2951; e-ISSN: 2503-2372 
Selanjutnya dilakukan pengukuran pada kondisi kedua, dimana air yang masuk kedalam tower sampai penuh dan air meluap keluar. Hal ini menandakan air yang masuk kedalam tower melebihi dari air yang disalurkan oleh pipa penstock. Kondisi ini akan terjadi bila suplai air berlebih dari yang digunakan pada saat musin hujan, tetapi desain piko hidro tersebut tidak mampu mengubah seluruh energi air yang ada menjadi energi mekanik. Hasil pengukuran pada kondisi ke-2 ini terlihat pada Gambar 9. Diman rpm rata-ratanya sebesar 129,75 untuk data ke-1 dan sebesar 129,58 untuk data yang ke2. Hasil ini memperlihatkan kedua data didapatkan hasil yang mendekati sama.

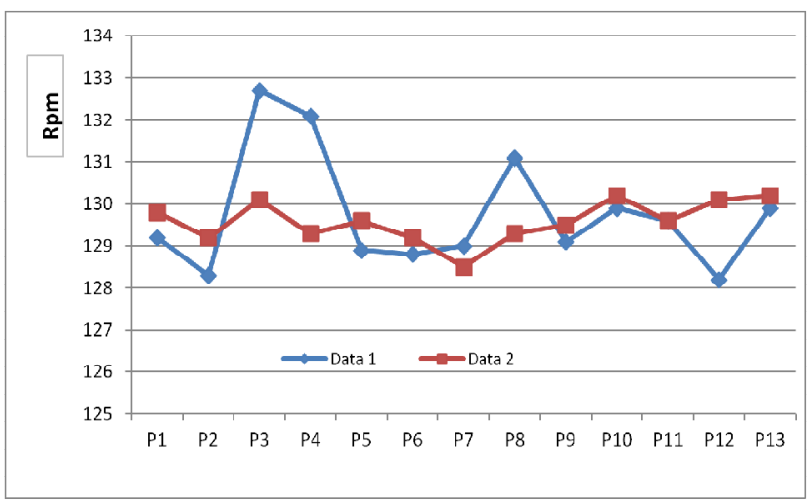

Gambar 9. Hasil pengukuran rpm pada saat toer penuh air

Selanjutnya bila kita bandingkan antara data pengukuran yang pertama dengan yang kedua maka didapatkan selisih rpm dengan rata-rata sebesar 7,06 sampai dengan 5,53. Nilai ini meunujukkan bahwa rpm rata-rata dari turbin akan berkurang sebesar itu saat mesim kemarau. Sehingga energi listrik yang dihasilkan juga akan berkurang. Selisih rpm yang dihasilkan terlihat pada Gambar 9.

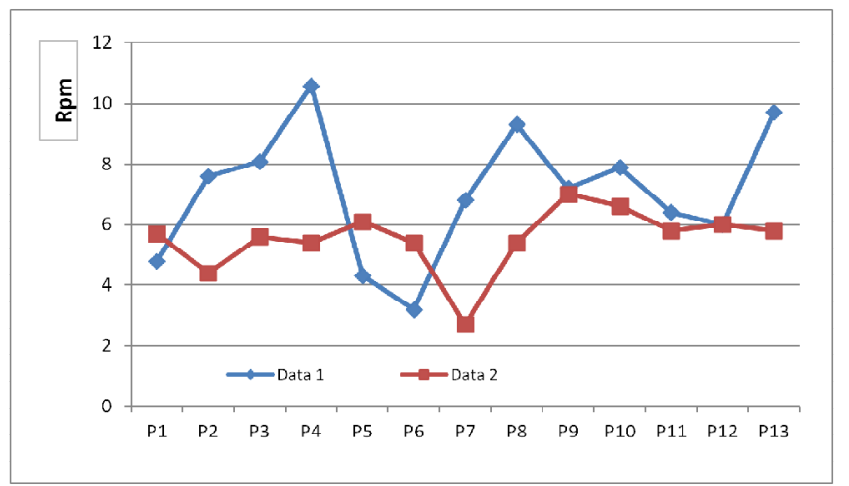

Gambar 10. Selisih Hasil pengukuran rpm pada saat tower penuh dan tidak penuh air

Mengingat penelitaian ini masih berlanjut, perbaikan disana sini masih dilakukan untuk mendapatkan hasil yang maksimal dari energi listrik yang dihasilkan generator, saat ini hasil pengkuran daya yang dihasilkan kurang lebih 100 Watt. Hal ini disebabkan karena peralatan lainya dalam kondisi belum terpasang lengkap.

Hasil pengukuran ini sudah menandakan bahwa turbin cross flow yang digunakan sudah sebagai pembangit piko hidro mampu menghasilkan rpm maksimal sebesar 130,1 dengan kondisi air yang ada pada tower dalam kondisi penuh.

\section{KESIMPULAN}

Piko hidro yang dirancang dalam penelitian ini terbukti mampu menghasilkan rpm tubin yang maksimal sebesar 130 . Sedangkan rata-rata rpm turbin sebesar 129,75 didapatkan bila tower air dalam kondisi penuh, yang dapat diasumsikan dalam kondisi musim hujan. Untuk mampu menghasilkan putaran pada generator dengan rpm sebesar 1500, maka perkalian antar fulley turbin dan fuley generator dengan rasio perbandingan 1 : 12. Namun karena saaat pengukurang talikipas dalam kondisi basah, maka masih memungkinkan terjadinya spil dan guri-rugi yang timbul.

\section{UCAPAN TERIMA KASIH}

Penulis menyampaikan ucapan terimakasih kepada Kementrian Ristek Dikti atas dukungan pendanaan penelitian Hibah Bersaing melalui LPPM Universitas Udayana tahun anggaran 2015 dengan surat perjanjian penugasan pelaksanaan no. 311-107/UN14.2 /PNL.01.03.00/2015 tanggal 30 Maret 2015 dan dilanjutkan pada tahun 1916.

\section{REFERENSI}

[1] L. Jasa, P. Ardana, and I. N. Setiawan, "Usaha Mengatasi Krisis Energi Dengan Memanfaatkan Aliran Pangkung Sebagai Sumber Pembangkit Listrik Alternatif Bagi Masyarakat Dusun Gambuk -Pupuan-Tabanan," in Proceding Seminar Nasional Teknologi Industri XV, ITS, Surabaya, 2011, pp. B0377-B0384.

[2] S. Phrakonkham, G. Remy, D. Diallo, and C. Marchand, "Pico vs Micro Hydro based Optimized Sizing of a Centralized AC Coupled Hybrid Source for Villages in Laos," Energy Procedia, vol. 14, pp. 1087-1092, 2012.

[3] P. Maher and N. Smith, "Pico Hydro for Village Power A Practical Manual for Schemes up to $5 \mathrm{~kW}$ in Hilly Areas," Project UK Departement for International Development (DfID), May 2001.

[4] L. Jasa, A. Priyadi, and M. H. Purnomo, "PID Control for Micro-Hydro Power Plants based on Neural Network," 2012.

[5] L. Jasa, A. Priyadi, and M. H. Purnomo, "An Alternative Model of Overshot Waterwheel Based on a Tracking Nozzle Angle Technique for Hydropower Converter | Jasa | International Journal of Renewable Energy Research (IJRER)," Ilhami Colak, vol. 4, no. No. 4, pp. 10131019, Dec. 2014.

[6] T. Sakurai, H. Funato, and S. Ogasawara, "Fundamental characteristics of test facility for micro hydroelectric power generation system," presented at the International Conference on Electrical Machines and Systems, 2009. ICEMS 2009, 2009, pp. $1-6$.

[7] M. A. A. Syed, M. M. N. Ali, F. S. Hossain, S. A. Haque, and A. H. Siddique, "Prospect of a Pico Hydro power plant based on irrigation pump in perspective of rural areas in Bangladesh," in 2011 2nd International Conference on Electric Power and Energy Conversion Systems (EPECS), 2011, pp. 1 -6.

[8] O. Yadav, N. Kishor, J. Fraile-Ardanuy, S. R. Mohanty, J. I. Perez, and J. I. Sarasua, "Pond head level control in a run-of-river hydro power plant using fuzzy controller," in 2011 16th International Conference on Intelligent System Application to Power Systems (ISAP), 2011, pp. 1-5.

[9] S. J. Williamson, B. H. Stark, and J. D. Booker, "Low head pico hydro turbine selection using a multi-criteria analysis," Renew. Energy, vol. 61, pp. 43-50, Jan. 2014.

[10] C. A. Mockmore and F. Merryfield, "The Banki Water Turbine," Bull. Ser. No25, Feb. 1949.

[11] L. Jasa, "Investigasi Sudut Nozzle dan Sudut Kelengkungan Sudu Turbin Air Untuk Peningkatan Efisiensi Mikro Hidro," Institut Teknologi Sepuluh Nopember, Surabaya, 2016. 